\title{
Changes in Callosal Angle After Successful Endoscopic Third Ventriculostomy Procedure in Pediatric Patients
}

\author{
Bahattin TANRIKULU, M. Memet OZEK \\ Acibadem Mehmet Ali Aydinlar University, School of Medicine, Department of Neurosurgery, Istanbul, Turkey \\ This study has been presented at the $33^{\text {th }}$ National Congress of Turkish Neurosurgical Society between 11 and 14 April 2019 at Antalya, Turkey.
}

Corresponding author: Bahattin TANRIKULU bahattintanrikulu@gmail.com

\section{ABSTRACT}

AIM: To determine whether callosal angle (CA) measurement, a diagnostic and prognostic tool used for normal-pressure hydrocephalus in adults, is a reliable radiological parameter for evaluating endoscopic third ventriculostomy (ETV) outcomes in pediatric patients.

MATERIAL and METHODS: Forty-seven pediatric patients with hydrocephalus who underwent successful ETV in our clinic between 2011 and 2015 were included in this study. Preoperative and postoperative three-month CA, lateral ventricle frontal horn (LVFH) width, Evans' index (EI), and frontal-occipital horn ratio (FOR) parameters were recorded, with changes analyzed using a paired-samples t-test.

RESULTS: There were 29 male and 18 female patients included within the cohort. For mean preoperative values, LVFH width was $58.8 \pm 14.9 \mathrm{~mm}$, El was $0.43 \pm 0.09$, FOR was $0.51 \pm 0.74$, and CA was $78.5^{\circ} \pm 36.4^{\circ}$. Separately, for mean postoperative values, LVFH width was $54 \pm 14.2 \mathrm{~mm}$, El was $0.39 \pm 0.09$, FOR was $0.47 \pm 0.07$, and CA was $104.5^{\circ} \pm 32.6^{\circ}$. The CA was increased and the LVFH width, El, and FOR were decreased in all patients within three months after surgery. The postoperative three-month change in CA was higher than those observed in the other parameters.

CONCLUSION: Changes in CA after successful ETV were dramatically higher than those in the other ventricular parameters. For this reason, we suggest CA be used as a radiological criterion during early radiological follow-up of patients after ETV.

KEYWORDS: Pediatric hydrocephalus, Callosal angle, Endoscopic third ventriculostomy

\section{INTRODUCTION}

$\mathrm{E}$ ndoscopic third ventriculostomy (ETV) is an effective treatment method for pediatric noncommunicating hydrocephalus with low complication rates in comparison with ventriculoperitoneal (VP) shunting $(4,21,25,35)$. Although ETV was first reported to be indicated in patients with aqueductal stenosis, it is now used for more diverse indications with different success rates depending upon the underlying pathology and the age of the patient $(19,20)$. Nevertheless, the follow-up of patients after ETV in terms of surgical success is challenging and controversial, especially in the pediatric setting (7) because young children typically cannot tell if their previous symptoms have been resolved or not after the ETV procedure (18). These patients may be followed up with using serial head circumference measurements but, again, the head size may not change dramatically within the months following surgery (18). Ophthalmological examination can yield an idea about intracranial pressure but it is not ideal to pursue an evaluation of the optic disc in babies with open fontanelles (23). Magnetic resonance imaging (MRI) is still one of the most reliable tools for evaluating the procedural success of ETV $(8,10,22)$. One may expect diminished ventricular volume and resolution of periventricular edema just after the ETV procedure such as is seen in the context of VP shunting. However, those changes in ventricular size may take several months to progress after ETV (33). There are also several MRI sequences available to show the patency of ETV stoma but 
the observation of such does not always mean that the ETV procedure was successful $(10,26)$, given that some of these patients may have far distal obstruction and/or cerebrospinal fluid (CSF) absorption problems $(28,36)$. For this reason, there is still no consensus regarding the radiologic criteria that must be followed to establish the effectiveness of the ETV procedure after surgery $(1,8,26)$. Given all of these limitations in the early postoperative radiological follow-up of those patients, a search for other possible radiological criteria to detect early radiological response after ETV is necessary.

Studies have been conducted previously that popularized callosal angle (CA) measurement in elderly patients with normal-pressure hydrocephalus (NPH) as a diagnostic and prognostic tool $(12,17,32)$. However, to our knowledge, no investigation on the collection of CA measurements in pediatric patients with obstructive hydrocephalus has been performed.

The aim of this study was therefore to evaluate the effectiveness of the preoperative and postoperative threemonth CA changes in determining the functionality of ETV among patients with noncommunicating hydrocephalus. We also sought to compare the number of postoperative changes in $\mathrm{CA}$ with the number of postoperative changes in lateral ventricle frontal horn width (LVFHw), Evans' index (EI), and frontal-occipital horn ratio (FOR).

\section{MATERIAL and METHODS}

This study was approved by the ethical committee of the Acibadem Mehmet Ali Aydinlar University School of Medicine. Informed consents were obtained from legal guardians of each patient.

Forty-seven children aged younger than 18 years who had undergone ETV for noncommunicating hydrocephalus in our institution between 2011 and 2015 were enrolled in this retrospective study. Patients with failed ETV and who required reoperation for hydrocephalus (either re-ETV or VP shunting) during the follow-up period as well as those who did not have preoperative and/or postoperative three-month MRI scans were excluded from this study. Ultimately, the mean follow-up period of the study cohort was $5.5 \pm 1.2$ years (range: $3.3-7.8$ years).

ETV procedures were performed through a right frontal burr hole located at the midpupillary line just in front of the coronal suture, using a rigid endoscope (Lotta system; Karl Storz SE \& Co. KG, Tuttlingen, Germany). The floor of the third ventricle was perforated by the tip of a bipolar electrode (28762 KB; Karl Storz SE \& Co. KG, Tuttlingen, Germany) without coagulation on and the stoma was dilated by inflatable double-balloon catheter (Integra Neurosciences, Sophia Antipolis, France) in all ETV procedures. Our routine follow-up policy for ETV patients is to obtain the first postoperative MRI scan at three months after surgery, obtain a second MRI scan at 12 months after surgery, and then conduct additional MRI scans every year thereafter. All preoperative scans evaluated in this study were taken within one month before ETV, while all postoperative scans evaluated in the study were taken within three months after ETV. Measurements of and calculations for
LVFHw, El, FOR, and CA were performed by two radiologists blinded to the patients' clinical data. Here, the LVFH was noted by measuring the maximal width of the lateral ventricle frontal horns; the El was calculated by dividing the maximum width of the lateral ventricle frontal horns by the maximal inner diameter of the skull at the same slice (9); the FOR was determined as the average of the frontal and occipital horn widths divided by the interparietal distance at the same slice (27); and the CA was measured at the level of posterior commissure on the coronal plane, which was perpendicular to the anteroposterior commissure line (Figure 1A, B). All calculations for each parameter are reported as average values of the measurements performed by both radiologists.

Intraclass correlation coefficient (ICC) calculations were performed to evaluate the interobserver reliability for LVFHw, $\mathrm{EI}, \mathrm{FOR}$, and CA. Preoperative and postoperative changes in LVFHw, El, FOR, and CA means were analyzed by pairedsamples t-test. Tests of significance were two-tailed and a p-value of 0.05 or less was regarded as statistically significant. All statistical analyses were performed using the Statistical Package for the Social Sciences version 20.0 software program (IBM Corp., Armonk, NY, USA).

\section{RESULTS}

There were 29 (61.7\%) male and 18 (38.3\%) female patients in the study cohort. The mean age of the included patients was $68 \pm 70$ months (range: 1-213 months). All patients had noncommunicating hydrocephalus. The etiology of hydrocephalus was congenital aqueductal stenosis in 36 (76.6\%) patients, tectal plate glioma in six (12.8\%) patients, suprasellar arachnoid cyst in two (4.3\%) patients, Blake' $s$ pouch cyst in two (4.3\%) patients, and intraventricular hemorrhage in one (2\%) patient (Table I).

The interobserver reliability values for LVFHw, El, FOR, and CA were $0.935,0.927,0.953$, and 0.977 , respectively. Regarding the mean values collected preoperatively, LVFHw was $58.8 \pm$ $14.9 \mathrm{~mm}$, El was $0.43 \pm 0.09$, FOR was $0.51 \pm 0.74$, and CA was $78.5 \pm 36.4^{\circ}$. In contrast, considering the mean values observed postoperatively, LVFHw was $54 \pm 14.2 \mathrm{~mm}$, El was $0.39 \pm 0.09$, FOR was $0.47 \pm 0.07$, and CA was $104.5 \pm 32.6^{\circ}$. Of note, the postoperative LVFHw, El, and FOR values were statistically lower than the corresponding preoperative values, whereas the postoperative CA value was statistically larger than the corresponding preoperative value. More specifically, there was a postoperative mean decrease of $4.8 \pm 9.2 \mathrm{~mm}$ (8.31\%) in LVFHw, $0.042 \pm 0.065(9.65 \%)$ in El, and $0.044 \pm$ $0.037(8.65 \%)$ in FOR, whereas a postoperative mean increase of $26.02^{\circ} \pm 20.98^{\circ}(49.28 \%)$ in CA was observed (Figure 2A, B and Table II).

\section{DISCUSSION}

ETV has been accepted as a safe and effective treatment method for pediatric hydrocephalus with a greater than $70 \%$ success rate, especially in patients with noncommunicating hydrocephalus $(3,13,15,16,21,34)$. Assessing the success of ETV remains a real challenge in pediatric patients because it 
Table I: Patient Characteristics

\begin{tabular}{lc}
\hline Characteristic & Value \\
\hline Age (months) & $68 \pm 70$ \\
\hline Male & $29(61.7 \%)$ \\
Sex & $18(38.3 \%)$ \\
Total & $47(100 \%)$ \\
\hline Etiology & $\mathbf{n ~ ( \% )}$ \\
\hline Aqueductal stenosis & $36(76.6 \%)$ \\
\hline Tectal plate glioma & $6(12.8 \%)$ \\
\hline Suprasellar arachnoid cyst & $2(4.3 \%)$ \\
\hline Blake's pouch cyst & $2(4.3 \%)$ \\
\hline IVH & $1(2 \%)$ \\
\hline Total & $47(100 \%)$ \\
\hline
\end{tabular}

IVH: Intraventricular hemorrhage. mainly relies on patient symptoms, neurological examination findings, and postoperative MRI scans $(7,18)$. Early postoperative MRI changes such as subarachnoid space widening, resolution of periventricular edema, and ventricular size reduction in patients with ETV are not as apparent as those in patients who underwent VP shunting (6).

It is supposed that there is a slow increase in CSF absorption through arachnoid granulations after ETV; as a result, the change in ventricular size would be very minor within the first three to six months after surgery $(11,24,33)$. Although there are sophisticated motion-sensitive MRI sequences such as spin-echo, turbo spin-echo, steady-state free precession, three-dimensional constructive interference in the steady state, reverse fast imaging with steady-state precession, spatial modulation of magnetization, and cine phasecontrast for the evaluation of ETV stoma, the identification of a functional ETV stoma does not always mean that the ETV procedure successfully treated the hydrocephalus (8). On the other hand, MRI procedures that include these sequences
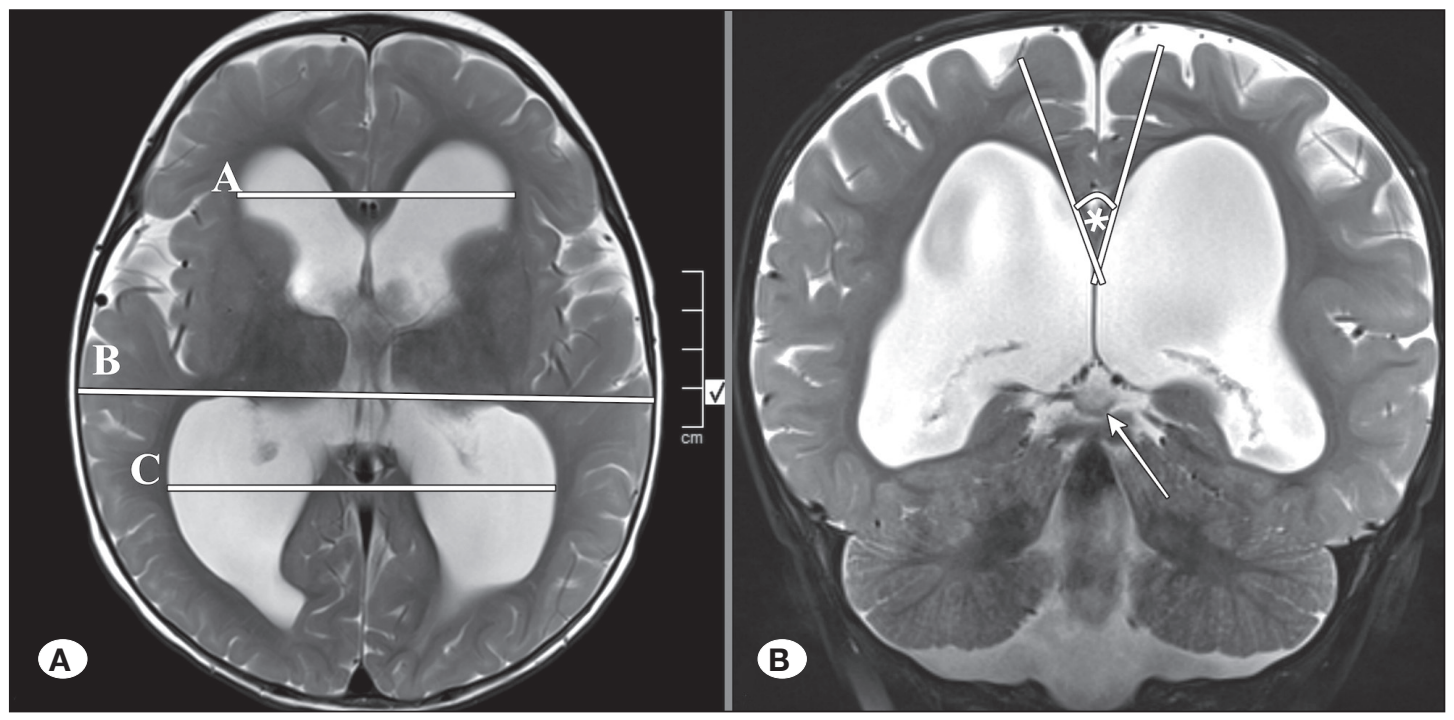

Figure 1:

A) $\mathrm{LVFHw}=\mathrm{A}, \mathrm{EI}=$ $\mathrm{A} / \mathrm{B}, \mathrm{FOR}=(\mathrm{A}+\mathrm{C}) / 2 \mathrm{~B}$.

B) The asterisk designates the CA measured at the level of the posterior commissure (arrow).
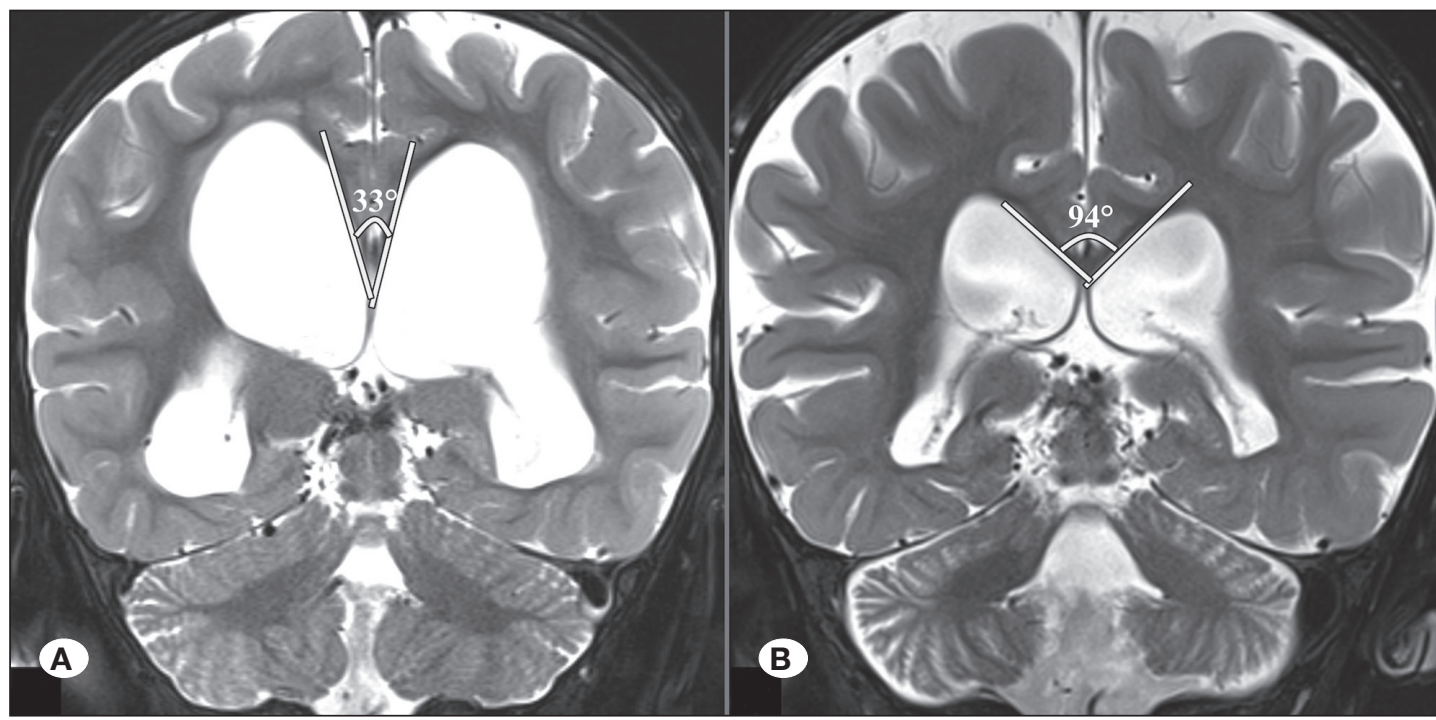

Figure 2:

A) Preoperative CA measurement $\left(33^{\circ}\right)$ of a patient with noncommunicating hydrocephalus. B) Pericallosal angle measurement $\left(94^{\circ}\right)$ of the same patient at three months after ETV, showing a dramatic increase. 
Tanrikulu B. and Ozek MM: Endoscopic Third Ventriculostomy

Table II: Pre-Operative and Post-Operative Measurements of CA, El, FOR and LVFH

\begin{tabular}{lccccc}
\hline & Pre-operative & Post-operative & $\begin{array}{c}\text { Post vs pre-operative } \\
\text { difference \%(95\%Cl) }\end{array}$ & $\begin{array}{c}\text { Post vs pre-operative } \\
\text { difference \% (95\%Cl) }\end{array}$ & p \\
\hline LVFHw & $58.8 \pm 14.9 \mathrm{~mm}$ & $54 \pm 14.2 \mathrm{~mm}$ & $\begin{array}{c}-4.8 \pm 9.2 \mathrm{~mm} \\
(-0.75,-0.21)\end{array}$ & $-8.31 \%(-11.7,-4.83)$ & $\mathbf{0 . 0 0 1}$ \\
\hline EI & $0.43 \pm 0.09$ & $0.39 \pm 0.09$ & $\begin{array}{c}-0.042 \pm 0.065 \\
(-0.061,-0.023)\end{array}$ & $-9.65 \%(-13.19,-6.11)$ & $<0.0001$ \\
\hline FOR & $0.51 \pm 0.07$ & $0.47 \pm 0.07$ & $\begin{array}{c}-0.044 \pm 0.037 \\
(-0.055,-0.033)\end{array}$ & $-8.65 \%(-10.65,-6.66)$ & $<0.0001$ \\
\hline CA & $78.5 \pm 36.4$ & $104.53 \pm 32.6$ & $\begin{array}{c}+26.02 \pm 20.98 \\
(19.85,32.18)\end{array}$ & $+49.28 \%(33.33-65.24)$ & $<0.0001$ \\
\hline
\end{tabular}

CA: Callosal angle, EI: Evans' index, FOR: Frontal-occipital horn ratio, LVFHw: Lateral ventricular frontal horn width. Minus designates post-operative decrease, whereas + designates post-operative increase.

may last at least 40 minutes and these sequences may not be available in all institutions (7). For this reason, neurosurgeons and radiologists need access to more practical and objective criteria during the early radiological follow-up of patients with ETV.

First radiological measurements of ventricles were performed on air encephalograms and El was defined as the frontal horn width divided by the interparietal diameter in 1942 (33). El is a widely used index but boasts limitations, especially in patients with larger occipital horns, and it has been suggested to be a poor measure of ventricular size (27). Ventricular brain ratio is another index shown to be the best nonvolumetric estimate of ventricular volume available at this time $(27,37)$. However, its calculation is time-consuming and not practical to conduct in daily outpatient clinic practice. O'Hayon et al. defined the FOR as the best correlate of ventricular brain ratio (27). It is a practical measurement for determining ventricular volume but existing knowledge in the literature about its utility during the early postoperative follow-up evaluation of patients with ETV is limited. Kulkarni et al. reported that mean FOR levels decrease in both successful and failed ETV patient groups and only $48 \%$ of patients with successful ETV procedure showed greater than a $15 \%$ reduction in FOR (24). For this reason, such may not be a functional parameter to be used in the early postoperative evaluation of ETV patients. LVFHw is one of the most frequently applied parameters to evaluate the size of lateral ventricles $(5,14)$. Schwartz et al. reported a $23 \%$ reduction in LVFHw following successful ETV. However, this study cohort was composed of both pediatric and adult populations and postoperative MRI schedules were highly variable (31).

CA was first defined by Benson et al. as a diagnostic parameter for NPH on air encephalograms (2). Ishii et al. performed the inaugural measurements of $\mathrm{CA}$ on $\mathrm{MRI}$ scans of patients with NPH, those Alzheimer's disease, and normal healthy individuals. They reported that a CA of less than $90^{\circ}$ is highly suggestive of $\mathrm{NPH}$. They also concluded that smaller CAs represent a predictor of better outcomes after VP shunting in $\mathrm{NPH}$ patients (17). To the best of our knowledge, there has been no report published concerning early CA changes in the pediatric population after successful ETV. In our study, there was an $8.3 \%$ mean decrease in LVFHw, 9.65\% mean decrease in $\mathrm{El}$, and $8.65 \%$ mean decrease in $\mathrm{FOR}$, whereas a $49.2 \%$ mean increase in CA within three months after successful ETV was reported. The changes in LVFHw, El, or FOR appear to be smaller in our patient cohort in comparison with in other studies $(24,25,27,30,31,33)$. This may be because we only included postoperative three-month control MRI scans and, during this short period of time, the degree of ventricular size reduction is expected to be limited $(11,24,33)$. Supporting this, previous studies included MRI scans obtained during longer postoperative periods in which higher reductions in ventricular volume may occur.

In the current study, the most dramatic postoperative change was observed in CA. For this reason, we proposed CA measurement to be a predictor of functional ETV procedure during early radiological follow-up of pediatric patients who showed persistent big ventricles with no clinical signs or symptoms of hydrocephalus after ETV. Since the difference between before and after surgery was dramatically high for CA in comparison with for LVFHw, El, and FOR, CA may be a convenient tool for deployment especially in patients who experience millimetric changes that cannot be documented or which could be easily missed by other ventricular parameters during routine daily outpatient clinic practice. CA measurement is also a more rapid tool to use in comparison with the assessment of ETV success using sophisticated and time-consuming MRI sequences since it can be measured on coronal- and sagittal-section T2-weighted MRI scans able to be obtained within just three minutes. Since many pediatric patients need anesthesia prior to extensive MRI, CA measurement from MRI sequences performed within a few minutes could decrease the need for anesthesia (29). For this reason, CA measurement may also be used in emergent situations for the evaluation of ETV success when the patient requires an emergent treatment decision and is not a good candidate for anesthesia. 


\section{CONCLUSION}

ETV is an effective treatment modality in pediatric hydrocephalus. Since postoperative ventricular size changes are slow in comparison to those in the VP shunt procedure, it is not easy to determine the functionality of ETV in the early postoperative period. In this study, we concluded that changes in CA after successful ETV are dramatically higher than those in other ventricular parameters (i.e., LVFHw, El, and FOR). For this reason, CA can be used to gather information about the functionality of ETV in asymptomatic pediatric patients with large ventricles during the early postoperative follow-up period.

\section{ACKNOWLEDGEMENT}

We would like to thank Dr. Alp Dincer and Dr. Erdem Yildiz, faculty members of Acibadem Mehmet Ali Aydinlar University University School of Medicine Department of Radiology, for their valuable contributions to measurement of radiological parameters discussed in this paper.

Preparation for publication of this article is partly supported by Turkish Neurosurgical Society

\section{REFERENCES}

1. Aleman J, Jokura H, Higano S, Akabane A, Shirane R, Yoshimoto T: Value of constructive interference in steadystate three-dimensional, Fourier transformation magnetic resonance imaging for the neuroendoscopic treatment of hydrocephalus and intracranial cysts. Neurosurgery 48:12911295, 2001

2. Benson DF, LeMay M, Patten DH, Rubens AB: Diagnosis of normal-pressure hydrocephalus. N Engl J Med 283:609-615, 1970

3. Brockmeyer D, Abtin K, Carey L, Walker ML: Endoscopic third ventriculostomy: An outcome analysis. Pediatr Neurosurg 28:236-240, 1998

4. Cinalli G, Sainte-Rose C, Chumas P, Zerah M, Brunelle F, Lot G, Pierre-Kahn A, Renier D: Failure of third ventriculostomy in the treatment of aqueductal stenosis in children. J Neurosurg 90:448-454, 1999

5. Denkhaus H, Winsberg F: Ultrasonic measurement of the fetal ventricular system. Radiology 131:781-787, 1979

6. Dincer A, Kohan S, Ozek MM: Is all "communicating" hydrocephalus really communicating? Prospective study on the value of 3D-constructive interference in steady state sequence at 3T. AJNR Am J Neuroradiol 30:1898-1906, 2009

7. Dincer A, Ozek MM: Radiologic evaluation of pediatric hydrocephalus. Childs Nerv Syst 27:1543-1562, 2011

8. Dincer A, Yildiz E, Kohan S, Memet Ozek M: Analysis of endoscopic third ventriculostomy patency by MRI: Value of different pulse sequences, the sequence parameters, and the imaging planes for investigation of flow void. Childs Nerv Syst 27:127-135, 2011

9. Evans AW: An Encephalographic ratio for estimating ventricular enlargement and cerebral atrophy. Arch Neur Psych 6:931-937, 1942
10. Fischbein NJ, Ciricillo SF, Barr RM, McDermott $M$, Edwards MS, Geary S, Barkovich AJ: Endoscopic third ventriculocisternostomy: MR assessment of patency with 2-D cine phase-contrast versus T2-weighted fast spin echo technique. Pediatr Neurosurg 28:70-78, 1998

11. Goumnerova LC, Frim DM: Treatment of hydrocephalus with third ventriculocisternostomy: Outcome and CSF flow patterns. Pediatr Neurosurg 27:149-152, 1997

12. Grahnke K, Jusue-Torres I, Szujewski C, Joyce C, Schneck M, Prabhu VC, Anderson DE: The quest for predicting sustained shunt response in normal-pressure hydrocephalus: An analysis of the callosal angle's utility. World Neurosurg 115:e717-e722, 2018

13. Grant JA, McLone DG: Third ventriculostomy: A review. Surg Neurol 47: 210-212, 1997

14. Hahn FJ, Rim K: Frontal ventricular dimensions on normal computed tomography. AJR Am J Roentgenol 126:593-596, 1976

15. Hirsch JF, Hirsch E, Sainte Rose C, Renier D, Pierre-Khan A: Stenosis of the aqueduct of Sylvius. Etiology and treatment. J Neurosurg Sci 30:29-39, 1986

16. Hopf NJ, Grunert P, Fries G, Resch KD, Perneczky A: Endoscopic third ventriculostomy: Outcome analysis of 100 consecutive procedures. Neurosurgery 44:795-804, 1999

17. Ishii K, Kanda T, Harada A, Miyamoto N, Kawaguchi T, Shimada K, Ohkawa S, Uemura T, Yoshikawa T, Mori E: Clinical impact of the callosal angle in the diagnosis of idiopathic normal pressure hydrocephalus. Eur Radiol 18:2678-2683, 2008

18. Isik $U$, Ozek MM: Clinical findings of children with hydrocephalus. In: Ginalli G, Ozek MM, Sainte-Rose C (ed), Pediatric Hydrocephalus. Springer, Cham, 2019:493-506

19. Javadpour M, Mallucci C, Brodbelt A, Golash A, May P: The impact of endoscopic third ventriculostomy on the management of newly diagnosed hydrocephalus in infants. Pediatr Neurosurg 35:131-135, 2001

20. Jones RF, Kwok BC, Stening WA, Vonau M: The current status of endoscopic third ventriculostomy in the management of non-communicating hydrocephalus. Minim Invasive Neurosurg 37:28-36, 1994

21. Jones RF, Stening WA, Brydon M: Endoscopic third ventriculostomy. Neurosurgery 26:86-91, 1990

22. Kim SK, Wang KC, Cho BK: Surgical outcome of pediatric hydrocephalus treated by endoscopic III ventriculostomy: Prognostic factors and interpretation of postoperative neuroimaging. Childs Nerv Syst 16:161-168, 2000

23. Ko MW: Optic disc swelling: Papilledema and other causes. In: Liu GT, Volpe NJ, Galetta SL (ed). Liu, Volpe, and Galetta's Neuro-Ophthalmology Diagnosis and Management. Elsevier, 2019:197-235

24. Kulkarni AV, Drake JM, Armstrong DC, Dirks PB: Imaging correlates of successful endoscopic third ventriculostomy. J Neurosurg 92:915-919, 2000

25. Kulkarni AV, Drake JM, Mallucci CL, Sgouros S, Roth J, Constantini S; Canadian Pediatric Neurosurgery Study G: Endoscopic third ventriculostomy in the treatment of childhood hydrocephalus. J Pediatr 155(2):254-259.e1, 2009 
Tanrikulu B. and Ozek MM: Endoscopic Third Ventriculostomy

26. Lev S, Bhadelia RA, Estin D, Heilman CB, Wolpert SM: Functional analysis of third ventriculostomy patency with phase-contrast MRI velocity measurements. Neuroradiology 39:175-179, 1997

27. O’Hayon BB, Drake JM, Ossip MG, Tuli S, Clarke M: Frontal and occipital horn ratio: A linear estimate of ventricular size for multiple imaging modalities in pediatric hydrocephalus. Pediatr Neurosurg 29:245-249, 1998

28. Oertel JM, Mondorf Y, Schroeder HW, Gaab MR: Endoscopic diagnosis and treatment of far distal obstructive hydrocephalus. Acta Neurochir (Wien) 152: 229-240, 2010

29. Parad RB: Non-sedation of the neonate for radiologic procedures. Pediatr Radiol 48:524-530, 2018

30. Pindrik J, Jallo Gl, Ahn ES: Changes in third ventricular size in pediatric patients undergoing endoscopic third ventriculostomy. Childs Nerv Syst 29:2027-2034, 2013

31. Schwartz TH, Yoon SS, Cutruzzola FW, Goodman RR: Third ventriculostomy: Post-operative ventricular size and outcome. Minim Invasive Neurosurg 39:122-129, 1996
32. Sjaastad O, Nordvik A: The corpus callosal angle in the diagnosis of cerebral ventricular enlargement. Acta Neurol Scand 49:396-406, 1973

33. St George E, Natarajan K, Sgouros S: Changes in ventricular volume in hydrocephalic children following successful endoscopic third ventriculostomy. Childs Nerv Syst 20:834838, 2004

34. Tuli S, Alshail E, Drake J: Third ventriculostomy versus cerebrospinal fluid shunt as a first procedure in pediatric hydrocephalus. Pediatr Neurosurg 30:11-15, 1999

35. Vries JK: An endoscopic technique for third ventriculostomy. Surg Neurol 9:165-168, 1978

36. Wagner W, Koch D: Mechanisms of failure after endoscopic third ventriculostomy in young infants. J Neurosurg 103:4349, 2005

37. Wyper DJ, Pickard JD, Matheson M: Accuracy of ventricular volume estimation. J Neurol Neurosurg Psychiatry 42:345350, 1979 